\title{
Problemas bioéticos en torno a la criatura anencefálica
}

\author{
PABLO VALENZUELA F. ${ }^{1}$ \\ 1. Hospital Clínico Universidad de Chile, Departamento de Obstetricia y Ginecología, Unidad de Neonatología, \\ Profesor Asistente, Diplomado en Bioética.
}

\begin{abstract}
Bioethical Problems related to Anencephaly

Anencephaly occurs every 4/1 000 newborns, it is incompatible with extrauterine life and can be dangerous for mother's life. In our society, we do not talk about the ethical question set by anencephaly, whom have not the total attributes of human being, not even the likelihood of thinking and autonomy. Parents and family pain is examinated critically at the time of decisions, something that among us is not regulated. The debate centers on the point of humanity related to anencephalic babies and the right to medical care. On the other hand, some suggestions to deal with this problem are given.

(Key words: Anencephaly, person, pain).
\end{abstract}

Rev Chil Pediatr 2008; 79 (3): 303-310

\section{RESUMEN}

La anencefalia se presenta sobre 4 por 1000 nacidos vivos, es incompatible con la vida extrauterina y puede representar un peligro para la vida de la gestante. No existe en nuestro medio una discusión sobre el problema deontológico que presenta el anencéfalo quien no tiene todas las características propias de un ser, que aún en potencia, pudiese llegar a desarrollar pensamiento y autonomía. El sufrimiento de la madre y consecuentemente del padre y grupo familiar se analiza como argumento para tomar decisiones que en nuestro medio no están protocolizadas. Se discute el problema de la persona humana en el anencéfalo, pilar fundamental en la adquisición de derechos que configuren su tratamiento y se sugieren líneas de trabajo para enfrentar el problema.

(Palabras clave: anencéfalo, deontología, persona, duelo).

Rev Chil Pediatr 2008; 79 (3): 303-310

Trabajo recibido el 31 de marzo de 2008, devuelto para corregir el 29 de abril de 2008, segunda versión el 07 de mayo de 2008, aceptado para publicación el 14 de mayo de 2008.

Correspondencia a:

Pablo Valenzuela F.

E-mail:pvalenzuelaf@gmail.com 


\section{Descripción del problema clínico}

\section{Embriología y diagnóstico}

La anencefalia está constituida por la ausencia de los huesos de la calota, hemisferios cerebrales, sistema límbico y cerebelo. Hay malformaciones vertebrales cervicales, del agujero magno y respiratorias superiores. La hipófisis por lo común está ausente. Esta malformación es incompatible con la vida extrauterina. Habitualmente la muerte se produce in útero, pero cuando hay un parto con feto vivo, habrá actividad cardíaca durante algunos momentos y muy raramente una sobrevida de más de una hora.

El polihidramnios es frecuente. Estos fetos pueden llegar a término. No hay excusa para no hacer el diagnóstico pues a las 18 semanas, la malformación da señales inequívocas y posteriormente hay certeza diagnóstica.

La etiología es multi factorial; nutricional, ácido fólico y vitamina B12; antagonistas del ácido fólico (agua nitratada); hipertermia materna al momento del cierre del tubo neural.

\section{Incidencia}

Cuatro embarazos cada 1000 nacidos. En Chile según el ECLAMC era de 6,4\%o entre 1982 y 1989 bajando a 3,18\%o entre 2001 y 2002, luego de la introducción del ácido fólico en la harina para el pan $^{1}$.

\section{Evolución del gestado}

El anencéfalo crece y se desarrolla en forma semejante a un niño normal, fuera de sus malformaciones evidentes. La madre percibe sus movimientos desde la semana 22; tienen actividad electroencefalográfica, pero carecen completamente del sistema que permite experimentar dolor o sensaciones ${ }^{2}$. A término, pueden tener un peso normal. Su parto será muy dificultoso y potencialmente peligroso para la madre.

\section{Los padres durante el embarazo}

En el Consultorio de Asistencia Perinatal ${ }^{3}$ del Hospital Clínico de la Universidad de Chile, (CAP) desarrollamos un protocolo de asistencia a los padres que sufren de esta y otras situaciones similares y la descripción de lo que sigue es extraída de nuestra base da datos.

El diagnóstico se realiza entre las 12 y las 20 semanas de gestación y viene siempre acom- pañado del pronóstico de una muerte ineludible. Los padres, de no ser atendidos especialmente, derivarán a búsquedas de información de índole variada y a formarse ideas y proyecciones muchas veces alejadas de la realidad. Reciben todo tipo de consejos, desde el aborto hasta los eventos milagrosos y cursan progresivamente todas las etapas del duelo de una muerte, antes que ella se produzca.

Las madres experimentan una disociación, viviendo alternativamente con un niño sano y luego con un niño que va a morir. Para ella la inexistencia de ayuda dejará secuelas por largos años. Los padres, a veces rechazan tajantemente el embarazo, lo niegan o acompañan a sus mujeres en forma intuitiva. Son frecuentes las alteraciones laborales y efectos en la vida de pareja que pueden llevar a rupturas y separaciones. Esta situación se extiende al resto de la familia y puede tener repercusiones en los próximos niños por nacer ${ }^{4}$.

\section{Nacimiento}

El nacimiento es un evento contradictorio, pues el que nacerá lo hace para morir. El consuelo de algunos minutos de sobre vivencia no cambia en nada la perspectiva del evento y los padres que no estén preparados experimentarán una sensación de pavor y desesperación.

El niño anencéfalo es horrible (así lo refieren las madres, ellas manifiestas la sensación de algo horroroso [textual]) y desde muy antiguo era ocultado a los padres. A veces el padre lo examinaba antes de la sepultación. En la actualidad, el registro nacional de mortinatos obliga a la sepultación de estos seres cuando nacen después de las 24 semanas.

Dentro del protocolo del CAP se ha desarrollado una técnica para aminorar el efecto estético del anencéfalo de modo que los padres puedan estar en contacto con el y realizar un duelo adecuado.

\section{Métodos usados en la resolución del problema}

\section{Aborto}

En numerosos países el recurso del aborto es la solución de esta situación ${ }^{5}$. El aborto "terapéutico" está presente en la mayoría de 
los países americanos y, desde luego, europeos. En nuestro país el aborto es penado por la ley.

\section{Adelanto del parto a las 24 semanas de gestación}

En 2001, la Corte Suprema Argentina tomó una decisión inédita en la jurisprudencia argentina: autorizó la inducción del parto de una mujer embarazada de 7 meses que llevaba en el útero un feto con anencefalia ${ }^{6}$.

\section{Atención del parto a demanda de la situación obstétrica}

Los padres, o son sorprendidos por el diagnóstico, o llegan al parto sin preparación alguna con el consiguiente traumatismo psicológico y vivencial, para ellos y para su familia. Los equipos profesionales actúan en forma intuitiva sin preparación especial para una situación en extremo compleja y que puede traer consecuencias a largo plazo que afecten a todo el grupo familiar ${ }^{4}$.

\section{Atención del parto previa preparación por equipos multiprofesionales}

Esta es la solución en la Maternidad del Hospital Clínico de la Universidad de Chile y los relatos de los padres atendidos y el desarrollo posterior de sus grupos familiares parecen avalar la necesidad de institucionalizar este tipo de procedimientos.

\section{Duelo post parto}

En el período post parto la madre podría quedar rodeada de otras madres con sus hijos, situación intolerablemente dolorosa. El duelo afecta a todo el período de puerperio en que tiene que revertirse toda la preparación que la biología del embarazo instala en la madre para recibir al hijo.

\section{Impacto en la familia}

El duelo frente al anencéfalo tiene muy escasa divulgación en nuestro medio. Ha sido in extenso estudiado en Argentina. Eva Gilberti ${ }^{7}$, describe el conflicto y daño psíquico de la madre portadora del anencéfalo. "Desde una perspectiva que analice el psiquismo de quienes engendraron a la criatura que se tornará anencefálica, es posible proponer la tesis del daño psíquico como padecimiento de la familia que transita por ese sufrimiento".

Los padres presentan problemas de pareja y laborales manifestando a veces incapacidad de realizar sus labores normales. Los hermanos, enferman, disminuyen su rendimiento escolar y caen a veces en crisis de ansiedad e inapetencia.

\section{Posibilidades de manejo del duelo}

En la salud pública prácticamente no se dispone de profesionales que puedan atender a estos padres. El tratamiento psiquiátrico o psicológico es de alto costo.

\section{Efectos a distancia en el tiempo}

La muerte de un niño se acompaña de un aumento de todas las muertes de las madres y un ligero aumento en la mortalidad temprana de causas no naturales en los padres. El estrés psicológico puede afectar el pronóstico de la salud por diferentes vías ${ }^{8} \mathrm{y}$ aumentar el riesgo de muertes no naturales. Puede llevar a comportamientos de estilo de vida adversos que pueden afectar la mortalidad.

\section{Problemas principales que presenta la anencefalia}

\section{Desconocimiento del tema en la sociedad en general}

Hay en otros países una amplia discusión, especialmente en Argentina en donde el debate se ha realizado en el nivel legislativo ${ }^{9-11}$. En Chile el diagnóstico de la anencefalia se incluye como un tema dentro de las discusiones del aborto terapéutico y como acápite en textos legales pero no como un problema que afecta integralmente a las personas y familias. Buscando electrónicamente en Chile aparecen 362 documentos sobre anencefalia; sólo tres tienen algún contenido bioético, el resto principalmente dedicado al ácido fólico. De los artículos de contenido bioético, ninguno se explaya sobre la problemática de la madre o de la familia. Una búsqueda dirigida al Congreso Nacional y Cámara de Diputados no arrojó ningún resultado. 
El tema de la anencefalia no está incluido en ningún tipo de discusiones o proyectos de ley.

En las Guías Nacionales de Neonatología 2005, editadas por el Gobierno de Chile y el Ministerio de Salud, hay tres líneas para la anencefalia sin ninguna aproximación o consideración sobre el tratamiento del problema ni mención alguna sobre los dilemas de los padres $^{12}$.

\section{Desinformación de los padres}

Internet sólo consigue aumentar la ansiedad sobre la realidad que están viviendo y el exceso de información llevará a una mayor desinformación y deformación de la propia realidad.

\section{Impacto sobre el medio asistencial}

Las malformaciones congénitas de carácter letal tienen un fuerte impacto sobre las personas que trabajan atendiendo o recibiendo estos pacientes.

\section{Problemática bioética}

Status ontológico del anencefálico

¿Qué es un anencéfalo? La pregunta constituye el pilar fundamental de toda la cuestión.

El anencéfalo es un ser vivo. Ello no se discute. Es un ser humano. Lleva el genoma humano en su integridad. Y como tal tiene todos los derechos básicos de los seres humanos.

El anencéfalo es una persona. Dudoso; deberemos definir "persona humana".

El concepto de persona es una entidad filosófica sobre el que se fundamenta al valor ético que se otorga a un recién nacido. Los anglosajones hablan del ser humano y el ser persona, la primera de índole biológica y la segunda filosófica. Según Couceiro estas "son dos cuestiones formalmente distintas y no hay ninguna razón apriorística que nos permita suponer respuestas coincidentes" 13

Para las culturas semíticas y específicamente la hebrea, el hombre constituía un todo, cuerpo, espíritu, energía y trascendencia.

Los griegos separan el cuerpo de la psique y Aristóteles elabora la teoría del alma derivada de la animación de la vida. Para ellos la "persona" era una entidad aparte, era un atributo entregado posteriormente a la animación y aun a la presencia del alma. Se llegaba a ser persona en el interactuar dentro del mundo y esta "personalidad" se constituyó como una entidad de tipo filosófico que con el tiempo pasó a representar toda la potencia del individuo situado dentro de su mundo.

La definición de Boecio "sustancia indivisa de naturaleza racional" (siglo IV) dio el golpe final al lanzarla dentro de la Escolástica, pensamiento que marcó con T. De Aquino la concepción del hombre "occidental". La "persona" pasó así a ser un concepto metafísico indemostrable pero importante para el ordenamiento jurídico, desde el Código Romano en adelante.

En el siglo XVI para Kant la persona no es una cosa, un tipo de naturaleza, sino "la libertad y la independencia de la naturaleza". Persona es el ser capaz de darse a si mismo una norma moral.

Se ha buscado el inicio de la persona en el sustrato biológico desde los comienzos de la vida humana. Según Carlos Valenzuela Y., se iniciaría la vida humana cuando un genoma humano inicia su inter actuación con el medio propio para su expresión" "Persona no es un concepto científico sometible a prueba factual y tiene tal diversidad ideológica-cultural que es imposible poner de acuerdo a los proponentes". Y afirma "No es consistente que se plantee que una ética racional o intuitiva esté basada en el conocimiento científico".

Para los que presuponen la existencia de la persona, ésta iniciaría su existencia:

A) al momento de la fecundación: penetración del espermio al óvulo; b) al momento de la singamia: (18 a 20 horas después de fecundación); c) al momento de la implantación o anidación (día 7 a 14); d) al momento de la formación del sistema nervioso central (día 15 a 40); e) al momento del nacimiento (separación efectiva de la madre); f) al momento de ser viable.

Alejandro Seráni en "El estatuto antropológico del embrión humano"15 aun cuando acepta que los conceptos aristotélicos están en cierta forma obsoletos, sigue su método lógico en el análisis que hace de el problema de la vida humana. "En efecto, el conocimiento intelectual y la libertad revelan en el hombre un 
constitutivo ontológico que trasciende al determinismo y a la corruptibilidad de la materia corpórea. A este modo original y propio de ser sujeto el pensamiento clásico llamó persona. Es persona todo individuo cuyo sujeto es racional e inmaterial en cuanto a su raíz y en tanto que racional, libre". $\mathrm{Y}$ concluye"el surgimiento de la persona humana en la existencia, al igual que para todo ente natural, constituye un evento instantáneo y no un proceso...

Según Cruceiro ${ }^{14}$, el definir la persona en términos de la naturaleza y derivar juicios normativos a partir de premisas descriptivas no sería un proceso debido (falacia naturalista), desde que Hume afirmó que de las premisas fácticas o de hecho no se pueden deducir deberes u obligaciones morales.

Termina Couceiro: nuestras obligaciones morales de no maleficencia varían con la realidad biológica de la persona " $y$ son mínimas cuando falta toda capacidad intelectiva o todo potencial de relación con el entorno, como sucede, por ejemplo, en los neonatos anencefálicos".

El recién nacido, así, no es estrictamente persona al nacer; la sociedad le otorga la condición de tal como señal de respeto y de la valoración que hace de ese ser. "De esta manera se pueden otorgar derechos a realidades biológicas que no son estrictamente personas".

Dentro de la fenomenología, el carácter de persona consiste en ser capaz de comprender el sentido de las cosas. Xavier Zubiri plantea que el individuo al plantearse frente a las cosas, las actualiza pero al mismo tiempo se actualiza a si mismo. En esta actualización (aprehensión primordial de la realidad) el hombre adquiere su persona (suidad formal). Este vivir aprehendiendo lo llama "personeidad" y ello constituye permanentemente al individuo. La personalidad es la manifestación de la interacción con el medio cambiante. La personeidad se es y la personalidad se vive.

La personeidad requiere, para Zubiri, una estructura mínima (suficiencia constitucional). Tanto la personeidad como la suficiencia constitucional se alcanzarían con la expresión de los genes adecuados y en el momento adecuado. $\mathrm{Y}$ desde ese momento el ser sería merecedor de toda consideración (sujeto moral) a diferencia del incompleto que sólo sería un ser meramente natural.

Así el anencéfalo, aunque pertenezca a la especie humana por tener un "esquema de replicación" igual a los otros humanos, aunque su código genético pertenezca a la especie humana, sin embargo, no alcanzó a ser persona porque no se pudieron desarrollar ni siquiera las notas de una psique radical y primigenia, que posteriormente hubieran generado la intelección, el sentimiento y la volición ${ }^{16}$.

\section{Anencéfalo y persona humana}

El problema del anencéfalo es paradigmático de lo limítrofe en bioética. En el territorio de las malformaciones congénitas hay estados de desarrollo fetal que van desde lo informe hasta cuerpos casi completos y que sin embargo, nadie parece considerar como afectos a las propiedades de las personas:

Feto acardio-acraneo: Vive a expensas de su gemelo, no tiene corazón ni cráneo; Poliploidías: tres o cuatro series de cromosomas; Anencéfalos; Mola hidatiforme.

¿Cuál es el factor común que arrastran todos estos seres a pesar de ser tratados en formas tan diferentes?

Es la incapacidad definitiva de sobrevivir y desarrollar una intelección que les permita comprender y relacionarse de algún modo con la humanidad que los rodea. En otras palabras su personeidad puede ser puesta en duda aun cuando ameriten todo el respeto que se les deba como seres de nuestra especie.

\section{Derechos del anencéfalo}

Para nuestra legislación es persona todo nacido vivo desde la sección del cordón ${ }^{17}$. No discrimina sobre sus características morfológicas. Antes del nacimiento no existe civilmente $\mathrm{y}$ si muere in útero es como si no hubiese existido. La Constitución Política de la República de Chile dice en su artículo 19 inciso segundo "La ley protege la vida del que está por nacer"18. En la Convención de los derechos del niño firmada por Chile en 1990 no figura ninguna mención sobre el niño por nacer ${ }^{19}$. El Código Sanitario de Chile $^{20}$ en su Libro Primero Título I habla de la protección materno infantil pero no 
se pronuncia sobre el niño que está por nacer.

El problema de fondo no se toca, los malformados no están en la legislación chilena y la discusión no parece haber tenido cabida en nuestro medio legal y los derechos del anencéfalo serían los mismos de cualquier feto vivo o de cualquier niño que nace vivo. En lo primero, el feto no es sujeto derechos pues para nuestra legislación no es persona. Sólo está protegido por la Constitución en forma general y por la ley que penaliza el aborto. En lo segundo sería un niño como cualquier otro sujeto a las normas habituales de tratamiento médico. No hay normas para el tratamiento de los anencéfalos ni de otros malformados con pronóstico letal.

Aunque existe una Carta de los Derechos del $\mathrm{Niño}^{21}$, ella no hace mención al niño por nacer ni consideraciones especiales sobre este tipo de pacientes. No se plantea la discusión sobre la especial condición del anencéfalo en cuanto a sus derechos antes y después de nacer, salvo cuando se los equipara con un niño sano o "normal".

\section{Conflictos de derechos entre anencefálico, padres y familia}

No hay propiamente un conflicto de derechos entre la madre y su feto anencéfalo y sin embargo, existe de hecho una situación dolorosa y dramática que no ha sido cubierta por nuestro marco legal.

\section{Análisis del problema principal y de los valores involucrados}

\section{Problema principal}

Hay un ser humano que morirá indefectiblemente y que tiene características que no son uniformemente aceptadas como persona y sujeto de derechos.

\section{Valores involucrados}

De los padres

El derecho a la vida va parejo al derecho de dar vida. La madre tiene derecho a saber la verdad y si la verdad es dudosa, tiene derecho a saberlo en la medida de su capacidad de com- prensión. La salud física y mental es un valor que pueden verse comprometidas por el embarazo anencéfalo. El embarazo del anencéfalo cursa casi de regla con un polihidramnios que implica riesgo obstétrico para la madre ${ }^{22}$. Por otro lado la muerte in útero, frecuente en la anencefália es también una situación riesgosa para la madre ${ }^{23}$. El padre presente, con los mismos valores que la madre, sufre a la par, no siente al ser gestado y sólo puede trabajar con uno imaginario, deformado y condenado a morir.

\section{Del anencéfalo}

La vida del ser anencefálico es un valor que hay que resguardar a toda costa mientras no se acuerde o resuelva su verdadero status ontológico. En la actualidad se le adjudican todos los valores de las personas. Debe entonces ser protegido en la medida que lo necesite y merece ser sujeto de nuestros mejores esfuerzos.

La institución familiar es un valor importante. Está demostrada la influencia positiva del bienestar materno en el feto. Mientras no se dirima la cuestión, el anencéfalo goza del valor de ser persona y debe ser tratado como tal, aspirando a una muerte digna.

\section{De la familia}

La presencia de un embarazo anencéfalo distorsiona las vivencias familiares, hace desaparecer la alegría, obliga a una generosidad heroica, facilita conflictos entre los cónyuges o pareja, genera sentimientos de culpa y duelo muy difíciles de sobre llevar a menos que se cuente con ayuda especializada, cosa poco frecuente en nuestro medio.

\section{Derechos en "conflicto"}

Hay muy buenas razones de tipo científico y filosófico para postular la inexistencia de la persona en el anencéfalo. Por otro lado, algunos defienden la tesis de su existencia como en cualquier niño por nacer. En medio está una madre angustiada que lleva en su útero un ser que ella no identifica como ser humano, drama que sólo puede resolverse mediante la muerte. El derecho a la vida del anencéfalo puede entrar en conflicto con la estabilidad emocional de la madre y de todo el grupo familiar. La atmós- 
fera emocional que rodea estos casos está de tal grado perturbada que la suma de los daños podría parecer superior al mero derecho a la vida del anencéfalo. En otros países se ha resuelto beneficiar la autonomía de la madre frente a lo imposible y se acepta la inducción del parto a las 24 semanas de gestación.

\section{Soluciones posibles o cursos de acción}

\section{Solución mínima}

Consiste en no innovar, seguir con los procedimientos habituales que se usan a lo largo del país en espera que los afectados encuentran satisfacción en la atención prestada y que los esfuerzos asistenciales puedan ser dedicados a otros asuntos. Esta es una situación que se fundamenta en la realidad de numerosos lugares de atención de estas madres.

\section{Solución intermedia}

Debe ser paliativa, acoger a los afectados, acompañarlos, apoyarlos, instruirlos y tratarlos psicológica y psiquiátricamente cuando sea necesario. El anencéfalo seguirá siendo tratado como un ser afecto a los derechos de las personas normales y los padres seguirán sufriendo el trauma que les significa no poder dilucidar el status de su gestado y así fundamentar maduramente sus decisiones autónomas. Esta solución se fundamenta en una "aspiración" que surge del diálogo con los actores, que por falta de discusión del problema a niveles de decisión, se ven abocados dar soluciones que surgen de iniciativas muchas veces sin suficiente fundamento.

\section{Solución avanzada}

Plantearse frente a la integridad del problema, analizarlo multi disciplinariamente, discutirlo públicamente, estudiar a los afectados para decirles toda la verdad, que incluye nuestro profundo desconocimiento y desacuerdo, avanzar en el cambio de comportamientos asistenciales anacrónicos de modo de otorgar el máximo de beneficio a los padres y familiares, sea durante la gestación, parto o período posterior, salvaguardando la integridad de la criatura anencefálica. Esta solución de basa en la experien- cia del Consultorio de Asistencia Perinatal y está en marcha en nuestro Departamento.

\section{Referencias}

1.- López-Camelo J,Orioli I, Da Graca M, et al: Reduction of birth prevalence rates of neural tube defects alter folic acid fortification in Chile. Am J Med Genet A 2005; 1: 120-5

2.- Lee SJ, Meter Ralston H, Drey E, Partridge J, Rosen M: Fetal pain. A systematic multidisciplinary review of the evidence. JAMA 2005; 294 (8): 947-54.

3.- Valenzuela P, Ahumada S, González A, et al: Atención perinatal a padres con embarazo de riesgo vital neonatal. Rev Chil Obstetr Ginecol 2003; 68 (3): 21420 .

4.- Hughes P, Turton P, Hopper E, Evans C: Assesment of guidelines for good practice in psychosocial care of mothers after stillbirth: a cohort Study. Lancet 2002; 360 (9327): 114-8

5.- Forum sobre aborto en: http://www.google.cl/ search?Hl $=$ es\&q $=$ anencefalia + and + aborto + andlegislaci on\&btng $=$ Buscar + con + Google \&meta $=1 \mathrm{r} \%$ Dlang_es

6.- Clarín.com » Edición Viernes 20.06.2003 "Sociedad". Permiten adelantar el parto en casos de bebés con anencefalia. En: www.clarin.com/diario/2003/06/20/s03001.html

7.- Gilberti E: Anencefalia y daño psíquico en la madre. VII Jornadas Argentinas de Bioética - 8 al 10 de noviembre 2001. En: http://www.evagiberti.com/articulos/ anencefalia-y-dano-psiquico-en-la madre.html

8.- Li J, Precht D, Mortensen P, Olsen J: Mortality in parents after death of a child in Denmark: a nationwide follow-up study. The Lancet 2003; 361: 363-67.

9.- Rovaletti $M L$ : Anencefalia: un debate a asumir. Departamento de Humanidades Médicas, Facultad de Medicina, Universidad de Buenos Aires, Consejo Nacional de Investigaciones Científicas y Técnicas. En: http:// www.bioeticadebat.org/modules/mydownloads/ singlefile.php?Cid $=4 \&$ lid $=21$

10.- Sebastián M: Anencefalia: análisis ético bajo el concepto de "el feto como paciente". En: http:/latina. obgyn.net/sp/articles/Abril\%2000/Anenc\%20(1).htm

11.- Manzini JL: Aportes para una discusión bioética acerca de la interrupción del embarazo anencefálico. En: http://www.aabioetica.org/m2. Agosto 2001

12.- Malformaciones del tubo neural En: Guían Nacionales de Neonatología Ed. Mena P, Mulhlhausen G, Novoa P, Vivanco G. Gobierno de Chile, Ministerio de Salud, p: 257, 2005.

13.- Couceiro A: Consideraciones éticas en neonatología En: Deficiencia mental y comienzo de la vida humana. Javier Gafo. Edit. Universidad Pontificia de Comillas, Madrid, 2001, pag 169-86.

14.- Valenzuela $C$ : Sobre el origen ontogénico del ser humano. La solución científica. Rev Méd Chile 2007; 135: $121-6$. 
15.- Seráni A: Estatuto antropológico del embrión humano. Cuadernos de Bioética 1997; 8: 1063-73.

16.- Xubiri $J$ : La persona como forma de realidad: personeidad. En: Xubiri J, Sobre el hombre, Madrid, Alianza Editorial 1986; 103-222.

17.- Codigo Civil Chileno, Artículo 74.

18.- Constitución Política de Chile.

19.- Ministerio de Relaciones Exteriores de Chile, Decreto 380 del 14 de agosto de 1990. Promulga Convención sobre los Derechos del Niño.

20.- Código Sanitario. Editorial Jurídica de Chile, Santiago,
2007.

21.- Declaración de los Derechos del Niño. A.G. res 1386 (XIV), 14 U.N. GAOR Supp. (No. 16) p. 19, ONU Doc. A/4354 (1959).

22.- Germain A, Carvajal J: Fisiología del líquido amniótico. Polihidramnios y oligohidramnios. En: Pérez Sánchez, Obstetricia $3^{\text {ra }}$ ed, Santiago, Mediterráneo, 2001; 141-2.

23.- Embolía amniótica: http://www.medcenter.com/ Medscape/content.Aspx?Id $=1961 \&$ terms $=$ embolia + amniótica. 